Full Paper

\title{
Voltammetric Behavior of Antileukemia Drug Glivec. Part II - Redox Processes of Glivec Electrochemical Metabolite
}

\author{
Victor Constantin Diculescu, ${ }^{\mathrm{a}}$ Marilene Vivan, ${ }^{\mathrm{b}}$ Ana Maria Oliveira Brett ${ }^{\mathrm{a} *}$ \\ a Departamento de Química, Faculdade de Ciências e Tecnologia, Universidade de Coimbra, 3004-535 Coimbra, Portugal \\ b Hospital da Universidade de Coimbra, 3000 Coimbra, Portugal \\ *e-mail: brett@ci.uc.pt
}

Received: May 24, 2006

Accepted: June 28, 2006

\begin{abstract}
Glivec is a newly developed drug that belongs to the class of 2-phenylaminopyrimidine. It is a potent inhibitor of $A B L$-kinase, the main clinical manifestation of chronic myelogenous leukemia (CML). Based on its activity on CML, glivec is undergoing extensive evaluation for its activity against other tumor types. Detection and quantitation of glivec in biological fluids or cells is thus very important. The antileukemia drug glivec undergoes oxidation at glassy carbon electrodes and involves the formation of an oxidation product, $\mathrm{P}_{\text {glivec }}$. The adsorption of $\mathrm{P}_{\text {glivec }}$ at the GCE surface yields a compact monolayer allowing an electrochemical study of this compound adsorbed at the GCE surface. The reversible redox reaction of the adsorbed $\mathrm{P}_{\text {glivec }}$ is $\mathrm{pH}$ dependent and occurs with the transfer of 2 electrons and 2 protons. The surface standard potential and the rate constant of the heterogeneous electrochemical reaction were calculated using cyclic voltammetry to be $E^{\theta^{\prime}}=+180 \mathrm{mV}$ and $k=15.5 \mathrm{~s}^{-1}$, respectively. The total surface concentration of adsorbed $\mathrm{P}_{\text {glivec }}$ is $2.5 \times 10^{-12} \mathrm{~mol} \mathrm{~cm}$. The analytical determination of glivec was carried out by differential pulse voltammetric measurement of the anodic peak current corresponding to either the oxidation peak of glivec or the oxidation peak of $\mathrm{P}_{\text {glivec }}$ adsorbed on the GCE surface. The limits of detection of glivec and adsorbed $\mathrm{P}_{\text {glivec }}$ based on three times the noise level are $3.3 \times 10^{-8} \mathrm{M}$ and $2.9 \times 10^{-10} \mathrm{M}$, respectively.
\end{abstract}

Keywords: Glivec metabolite, Electrochemistry, Voltammetry, Standard potential, Rate constant, Adsorption

DOI: 10.1002/elan.200603592

\section{Introduction}

Glivec (Gleevec, STI 571, or imatinib mesylate) [1], Scheme 1, a derivative of 2-phenylaminopyrimidine, is a relatively small molecule with activity against protein tyrosine kinases $[1,2]$. Glivec is an inhibitor of the $B C R$ $A B L$ tyrosine kinase, a protein expressed by all patients with chronic myelogenous leukemia (CML) [4]. It is indicated for the treatment of patients with CML in blast crisis, accelerated phase, or in chronic phase after failure of interferon- $\alpha$ therapy [4]. Based on its activity on CML, glivec is undergoing extensive investigation for its activity against other tumor types $[5,6]$.<smiles>COS(=O)(=O)c1ccc(CN2CCN(C)CC2)cc1</smiles>

Scheme 1. Glivec chemical structure.

Electroanalysis 18, 2006, No. 18, 1808-1814
While the initial clinical results using glivec for the treatment of CML appear extremely promising, it was shown that problems such as the development of drugresistant disease develop with prolonged usage [7-9]. In addition, the efficacy of glivec in producing molecular complete remissions may be improved using combinations with traditional antineoplastic agents [7]. As a result, there is an ongoing need for the determination of glivec pharmacokinetics so that issues such as drug-drug or drug-biomolecular complexes interactions can be evaluated. Detection and quantitation of glivec in organic fluids or cells is thus very important.

In order to support pharmacokinetic studies with sufficient speed, suitable analytical procedures are required. A semi-automated solid-phase extraction procedure with liquid chromatography-tandem mass spectrometry was an initial development [10]. A number of laboratories reported the use of high-throughput bioanalytical procedures using liquid chromatography - tandem mass spectrometry or UV detection [10-14] for analytical determination and quantitation of glivec in human plasma. There are also reports on a capillary zone electrophoretic method for the determination of glivec and its main metabolite in human urine [15].

Electroanalytical methods are inexpensive, fast, and an appropriate voltammetric method that can allow direct 
measurements on biological samples with very little or no sample pretreatment. This is an enormous advantage when compared with other analytical techniques. Electroanalysis has been successfully used to quantitate different types of drugs, sometimes with very low detection limits [16].

Recently, it was shown that glivec and its main in vivo metabolite ( $N$-demethylated piperazine derivative) are strongly adsorbed onto a static mercury electrode. By using this property and accumulating these compounds on a hanging mercury drop electrode (HMDE), square-wave voltammetry was used to achieve higher sensitivities [17]. However, there is a high tendency for the use of less toxic methodologies and a reduction in the use of organic solvents and mercury since they result in high ecological costs.

Therefore, the electrochemical study of adsorbed glivec and its oxidation product at a glassy carbon electrode (GCE) was carried out in an attempt to establish a new and sensitive procedure for the analytical determination of this compound. Glivec is oxidized at a GCE, and this process involves the formation of an electroactive product, $\mathrm{P}_{\text {glivec }}$, which strongly adsorbs at the GCE, yielding a compact monolayer. The strong and irreversible adsorption of $\mathrm{P}_{\text {glivec }}$ at the electrode surface enables an electrochemical study of the adsorbed compound and a sensitive analytical determination of glivec can be achieved.

\section{Experimental}

\subsection{Materials and Reagents}

Glivec capsules of $100 \mathrm{mg}$ obtained from Novartis (Portugal) were used without further purification. Stock solutions of $100 \mu \mathrm{M}$ were prepared in purified water and stored at $-4{ }^{0} \mathrm{C}$. Solutions of different concentrations of glivec were prepared by dilution of the appropriate quantity in supporting electrolyte.

All supporting electrolyte solutions, Table 1, were prepared using analytical grade reagents and purified water from a Millipore Milli-Q system (conductivity $\leq 0.1 \mu \mathrm{S}$ $\mathrm{cm}^{-1}$ ).

Microvolumes were measured using EP-10 and EP-100 Plus Motorized Microliter Pipettes (Rainin Instrument Co. Inc., Woburn, USA). The $\mathrm{pH}$ measurements were carried out with a Crison micropH 2001 pH meter with an Ingold

Table 1. Supporting electrolytes, $0.1 \mathrm{M}$ ionic strength.

\begin{tabular}{ll}
\hline $\mathrm{pH}$ & Composition \\
\hline 2.6 & $\mathrm{HCl}+\mathrm{KCl}$ \\
3.6 & $\mathrm{HOAc}+\mathrm{NaOAc}$ \\
4.7 & $\mathrm{HOAc}+\mathrm{NaOAc}$ \\
5.5 & $\mathrm{HOAc}+\mathrm{NaOAc}$ \\
6.2 & $\mathrm{NaH}_{2} \mathrm{PO}_{4}+\mathrm{Na}_{2} \mathrm{HPO}_{4}$ \\
7 & $\mathrm{NaH}_{2} \mathrm{PO}_{4}+\mathrm{Na}_{2} \mathrm{HPO}_{4}$ \\
8.2 & $\mathrm{NaH}_{2} \mathrm{PO}_{4}+\mathrm{Na}_{2} \mathrm{HPO}_{4}$ \\
9.5 & $\mathrm{NaOH}+\mathrm{Na}_{2} \mathrm{~B}_{2} \mathrm{O}_{7}$ \\
12 & $\mathrm{NaOH}+\mathrm{KCl}$ \\
\hline
\end{tabular}

combined glass electrode. All experiments were done at room temperature $\left(25 \pm 1^{0} \mathrm{C}\right)$.

\subsection{Voltammetric Parameters and Electrochemical Cells}

Voltammetric experiments were carried out using a $\mu$ Autolab running with GPES 4.9 software, Eco-Chemie, Utrecht, The Netherlands. The experimental conditions for differential pulse voltammetry (DPV) were: pulse amplitude $50 \mathrm{mV}$, pulse width $70 \mathrm{~ms}$, scan rate $5 \mathrm{mV} \mathrm{s}^{-1}$. Measurements were carried out using a glassy carbon electrode (GCE) $(d=$ $1.5 \mathrm{~mm})$, with a $\mathrm{Pt}$ wire counter electrode, and $\mathrm{ag} / \mathrm{AgCl}$ $(3 \mathrm{M} \mathrm{KCl})$ electrode as reference, in a $0.5 \mathrm{ml}$ one-compartment electrochemical cell.

The GCE was polished using diamond spray (particle size $1 \mu \mathrm{m}$ ) before every electrochemical assay. After polishing, the electrode was rinsed thoroughly with Milli-Q water for $30 \mathrm{~s}$; then it was sonicated for 1 minute in an ultrasound bath and again rinsed with water. After this mechanical treatment, the GCE was placed in buffer electrolyte and various DP voltammograms were recorded until a steady-state baseline voltammogram was obtained. This procedure ensured very reproducible experimental results.

\subsection{Acquisition and Presentation of Voltammetric Data}

All the voltammograms presented were background-subtracted and baseline-corrected using the moving average application with a step window of $5 \mathrm{mV}$ included in GPES version 4.9 software. This mathematical treatment improves the visualization and identification of peaks over the baseline without introducing any artifact, although the peak intensity is in some cases reduced $(<10 \%)$ relative to that of the untreated curve. Nevertheless, this mathematical treatment of the original voltammograms was used in the presentation of all experimental voltammograms for a better and clearer identification of the peaks. The values for peak current presented in all plots were determined from the original untreated voltammograms after subtraction of the base line.

\subsection{Adsorption of Glivec Oxidation Product}

The adsorption of the glivec oxidation product, $\mathrm{P}_{\text {glivec }}$, at the GCE surface was carried out in a solution of $5 \mu \mathrm{M}$ glivec in pH 7.2 0.1 M phosphate buffer following three procedures:

- Procedure 1: The clean GCE was placed in the solution of glivec, and several DP voltammograms were recorded between 0 and $+1.40 \mathrm{~V}$ until a stable $\mathrm{P}_{\text {glivec }}$ oxidation peak was recorded.

- Procedure 2: The clean GCE was held for 2 min in the solution of glivec at a potential of $+0.90 \mathrm{~V}$;

- Procedure 3: After free adsorption for $2 \mathrm{~min}$ in the solution of glivec, the GCE was washed with a jet of 
deionized water and then transferred to $\mathrm{pH} 7.20 .1 \mathrm{M}$ phosphate buffer where it was conditioned at $+0.90 \mathrm{~V}$ during 2 min.

\section{Results and Discussion}

\subsection{Adsorption of $\mathbf{P}_{\text {glivec }}$}

The antileukemia drug glivec adsorbs on the GCE surface. The first DP voltammogram obtained in $\mathrm{pH} 7.20 .1 \mathrm{M}$ phosphate buffer after adsorption of glivec showed, as described in Section 2.4, two oxidation peaks at $E_{\mathrm{pa}}^{1}=$ $+0.75 \mathrm{~V}$ and $E_{\mathrm{pa}}^{2}=+1.05 \mathrm{~V}$, respectively, Figure 1 . On the second DP scan, a new anodic peak $3_{\mathrm{a}}$ appeared at $E_{\mathrm{pa}}^{3}=$ $+0.22 \mathrm{~V}$. This peak corresponds to the glivec oxidation product, $\mathrm{P}_{\text {glivec }}$, which strongly adsorbs on the electrode surface. Moreover, consecutively recorded DP voltammograms in buffer showed a very small decrease of peak 3 a corresponding to $\mathrm{P}_{\text {glivec }}$ oxidation current, only after 15 consecutive scans. Since no diffusion process occurs, disappearance of peaks $1_{\mathrm{a}}$ and $2_{\mathrm{a}}$ is due to total consumption of the glivec adsorbed onto the GCE after the first DP scan.

A detailed electrochemical study of the adsorbed $\mathrm{P}_{\text {glivec }}$ was carried out. For the optimization of adsorption conditions on the GCE surface, different procedures described in Section 2.4 were evaluated for various concentrations of glivec. After adsorption, the electrode was always washed with a jet of deionized water in order to remove the nonadsorbed molecules, and transferred to $\mathrm{pH} 7.20 .1 \mathrm{M}$ phosphate buffer where DP voltammograms were recorded. The voltammograms obtained with the three procedures were compared. Very reproducible results and higher oxidation peaks were obtained using Procedure 3, which was subsequently used to study the electrochemical behavior of $\mathrm{P}_{\text {glivec }}$ adsorbed on the GCE surface.

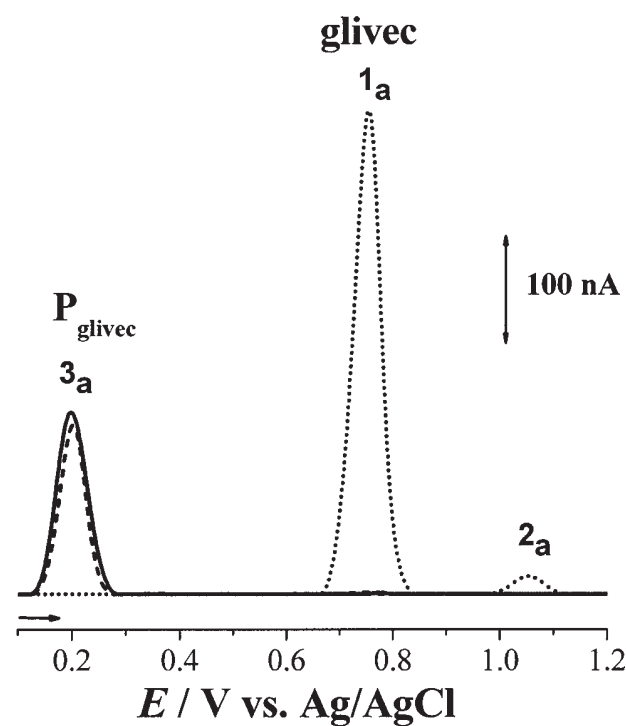

Fig. 1. DPV obtained with a GCE in $\mathrm{pH} 7.20 .1 \mathrm{M}$ phosphate buffer: $(\cdots . ..) 1^{\text {st }},(-) 2^{\text {nd }}$, and $(---) 15^{\text {th }}$ scan after free adsorption during 2 minutes in a solution containing $5 \mu \mathrm{M}$ glivec.
The adsorption of $\mathrm{P}_{\text {glivec }}$ from solutions with different concentrations of glivec was evaluated. The DP voltammograms were recorded in supporting electrolyte and the oxidation current of $\mathrm{P}_{\text {glivec }}$ was plotted vs. glivec concentration. Saturation of the electrode surface takes place at concentrations higher than $5 \mu \mathrm{M}$, Figure 2 . For this reason, the adsorption of $\mathrm{P}_{\text {glivec }}$ was always carried out in a $5 \mu \mathrm{M}$ glivec solution.

The determination of the degree of coverage of the electrode surface after adsorption of a specific compound is described by adsorption isotherms [19]. A number of isotherms have been proposed to describe adsorption equilibria at different electrode materials. From the results presented, it is difficult to determine the type of isotherm corresponding to the adsorbed $\mathrm{P}_{\text {glivec }}$ on the GCE surface. GCE is an isotropic material with amorphous characteristics. Thus, taking into account the existence of different types of surface adsorption sites and supposing there is no interaction between the adsorbed molecules, all conditions for a Temkin isotherm are fulfilled. As a particular case, if all adsorption sites are equal, a Langmuir isotherm would be obeyed [18]. However, it is correct, from the results obtained, to consider the formation of a monolayer of adsorbed $\mathrm{P}_{\text {glivec }}$ on the GCE surface.

\subsection{Differential Pulse Voltammetry}

The effect of $\mathrm{pH}$ on the oxidation peak potential, $E_{\mathrm{pa}}$, and on the peak current $I_{\mathrm{pa}}$ of $\mathrm{P}_{\text {glivec }}$ adsorbed onto the GCE surface was studied using DPV in $0.1 \mathrm{M}$ buffer supporting electrolytes with $1<\mathrm{pH} \leq 12$, Figure $3 \mathrm{~A}$.

The adsorption of $\mathrm{P}_{\text {glivec }}$ was carried out as described in Section 2.4, Procedure 3. The electrode was then placed in the electrolyte solution and the DP voltammogram was recorded immediately. Consecutive DPV scans in different

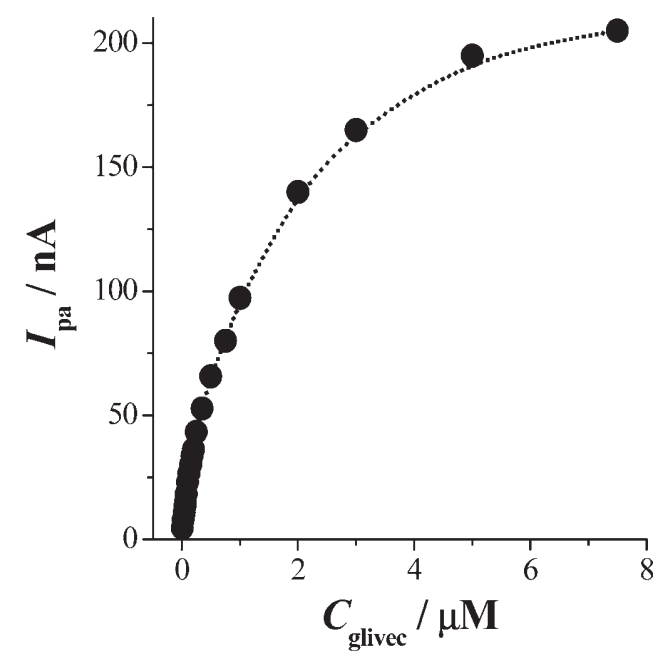

Fig. 2. Plot of $I_{\mathrm{pa}}$ of adsorbed $\mathrm{P}_{\text {glivec }}$ vs. glivec concentration in pH 7.2 0.1 M phosphate buffer. Adsorption of $P_{\text {glivec }}$ at the GCE surface was carried out as described in Procedure 3, Section 2.4. 
electrolyte solutions showed that the peak current is independent of the number of scans.

The oxidation of $\mathrm{P}_{\text {glivec }}$ is $\mathrm{pH}$ dependent and the variation of $E_{\mathrm{pa}}$ vs. $\mathrm{pH}$ is linear. The oxidation peak is displaced to lower potentials with increasing $\mathrm{pH}$, Figure 3B. The slope of the line corresponds to $58 \mathrm{mV}$ per $\mathrm{pH}$ unit, meaning that the same number of electrons and protons are involved in the oxidation mechanism. Nevertheless, in all electrolytes, the width at half height of the $\mathrm{P}_{\text {glivec }}$ oxidation peak was $W_{1 / 2}=$ $45 \mathrm{mV}$, which suggests that the oxidation of $\mathrm{P}_{\text {glivec }}$ occurs with the transfer of 2 electrons, hence also 2 protons.

Figure $3 \mathrm{~B}$ also shows the variation of the oxidation peak current with the $\mathrm{pH}$ of the supporting electrolyte. The maximum current was observed in $\mathrm{pH}$ 7.2 $0.1 \mathrm{M}$ phosphate buffer. For this reason, this electrolyte was used for further investigations.

\subsection{Cyclic Voltammetry}

Cyclic voltammograms of $\mathrm{P}_{\text {glivec }}$ adsorbed onto the GCE surface were recorded in $\mathrm{pH} 7.20 .1 \mathrm{M}$ phosphate buffer for
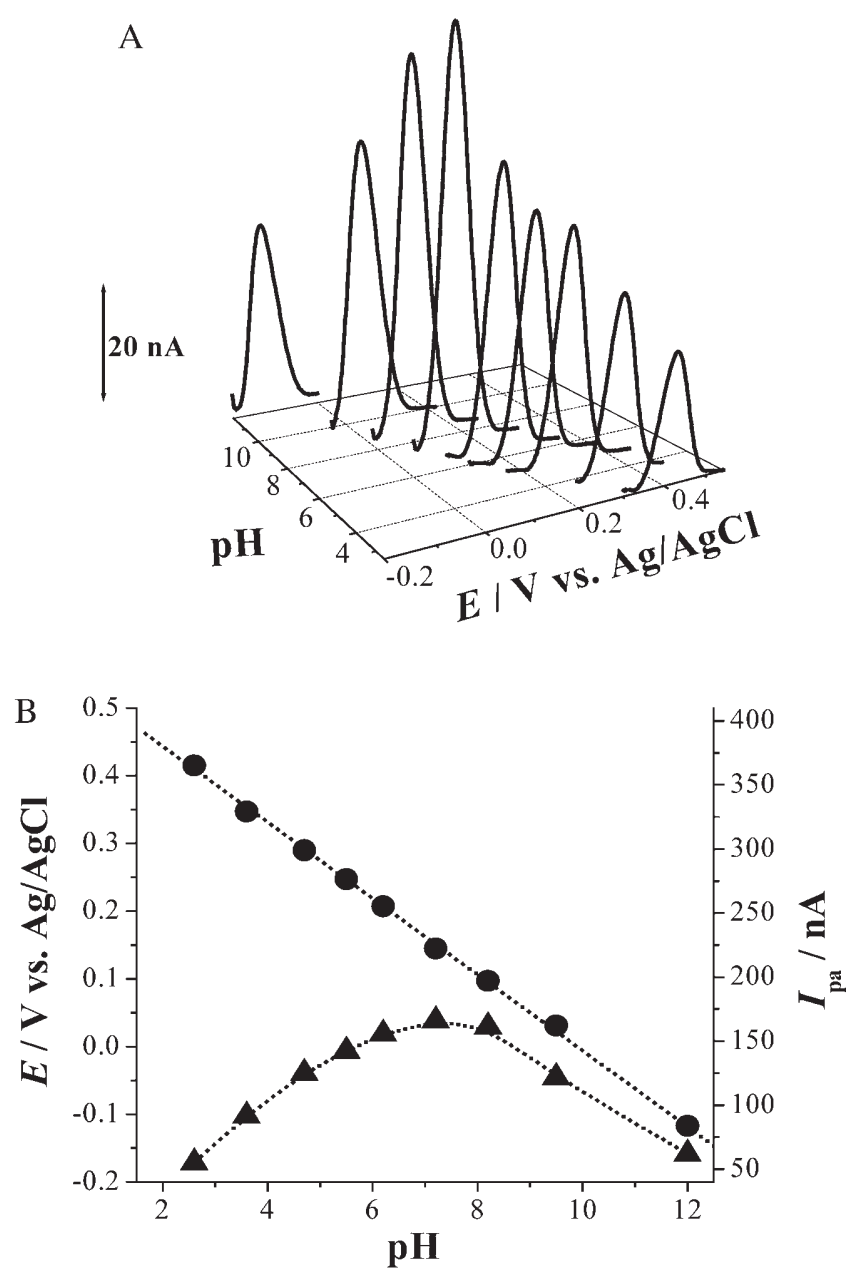

Fig. 3. A) $3 \mathrm{D}$ plot of DP voltammograms of adsorbed $\mathrm{P}_{\text {glivec }}$ as a function of $\mathrm{pH}$. B) Plot of $(\bullet) E_{\mathrm{pa}}$ and of $(\boldsymbol{\Lambda}) I_{\mathrm{pa}}$ of adsorbed $\mathrm{P}_{\text {glivec }}$ as function of $\mathrm{pH}$.

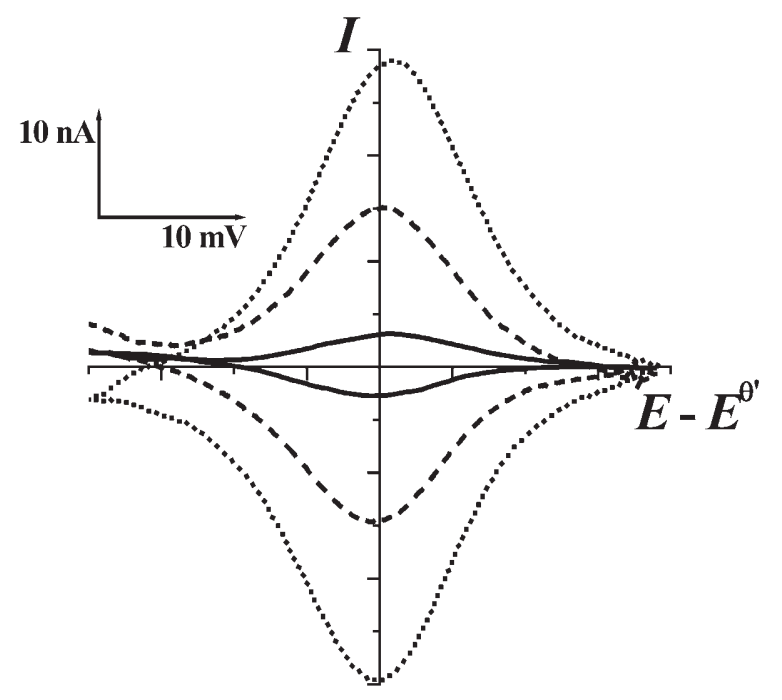

Fig. 4. Background-subtracted $\mathrm{CV}$ at (-) 5, (----) 10, and $(\cdots . .) .25 \mathrm{mV} \mathrm{s}^{-1}$ of adsorbed $\mathrm{P}_{\text {glivec }}$ in $\mathrm{pH} 7.20 .1 \mathrm{M}$ phosphate buffer.

scan rates between $5 \mathrm{mV} \mathrm{s}^{-1}$ and $5 \mathrm{~V} \mathrm{~s}^{-1}$. The adsorption was carried out as described in Section 2.4, Procedure 3. The voltammograms obtained for low scan rates, $5 \leq v \leq 250 \mathrm{mV}$ $\mathrm{s}^{-1}$, presented symmetrical wave shapes that confirm the reversible character of $\mathrm{P}_{\text {glivec }}$ oxidation, Figure 4.

For the lowest scan rate, $v=5 \mathrm{mV} \mathrm{s}^{-1}, W_{1 / 2}=48 \mathrm{mV}$; hence, the number of electrons transferred is equal to 2 [19]. Considering the slope of the plot of peak potential versus $\mathrm{pH}$, Figure 3B, the results obtained by DPV, that 2 electrons and 2 protons are exchanged during the redox reactions of $\mathrm{P}_{\text {glivec }}$, are confirmed.

The wave shape symmetry, as well as the linear dependence of the anodic and cathodic currents with increasing scan rates observed, is a characteristic of electrode processes of organic species irreversibly adsorbed at the electrode surface and with reversible charge transfer kinetics in which the energy of the reagent and of the product are equal [18]. In these processes there is no contribution from the diffusion of the species in solution towards the electrode surface, since the voltammograms were recorded in supporting electrolyte. The slight asymmetry between the experimental voltammograms obtained and those predicted by the theory for adsorbed species stems from background supporting electrolyte interactions and from the non-ideal behavior of adsorbed species [20].

For higher scan rates, $v \geq 250 \mathrm{mV} \mathrm{s}^{-1}$, there is an increasing separation between the oxidation and the reduction peak potentials with increasing scan rate, showing the loss of system reversibility, the process becoming rate-limited, Figure 5. The small increase of the anodic and cathodic current peak width at half height, $W_{1 / 2}$, and of anodic and cathodic peak potential separation, $\Delta E_{\mathrm{p}}$, with increasing scan rate can be attributed to slower charge transfer kinetics for higher values of $v$ [21].

Also, the peak currents increase with increasing scan rate. The nonlinear dependence of $I_{\mathrm{pa}}$ and $I_{\mathrm{pc}}$ for $v \geq 250 \mathrm{mV} \mathrm{s}^{-1}$, Figure $6 \mathrm{~A}$, is explained by considering the effect of very high 


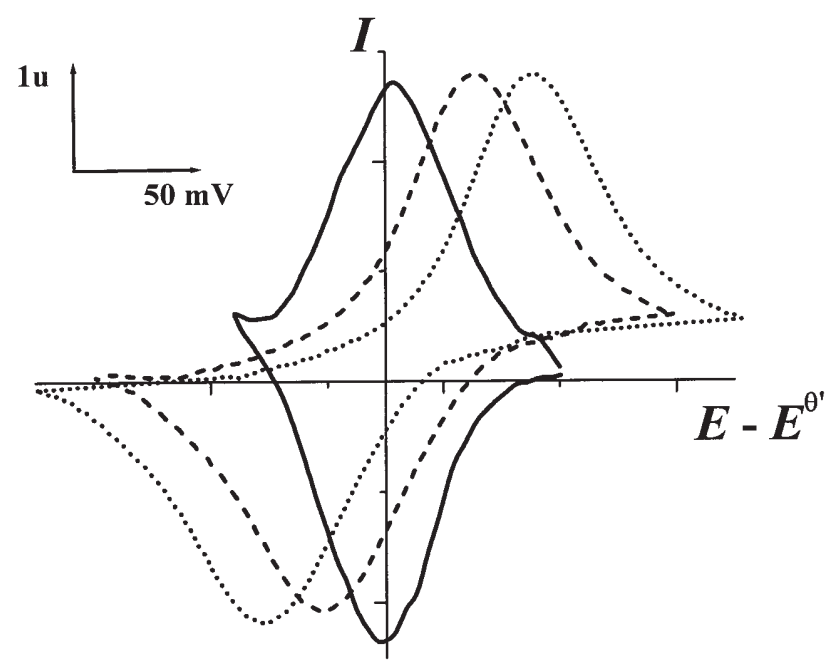

Fig. 5. Background-subtracted CV at (-) 0.005, (----) 1.5, and (…..) $5 \mathrm{~V} \mathrm{~s}^{-1}$ of adsorbed $\mathrm{P}_{\text {glivec }}$ in $\mathrm{pH} 7.20 .1 \mathrm{M}$ phosphate buffer; $1 \mathrm{u}$ of current represents $1.43 \mathrm{nA}$ for $5 \mathrm{mV} \mathrm{s}^{-1}, 435 \mathrm{nA}$ for $1.5 \mathrm{~V} \mathrm{~s}^{-1}$, and $1.1 \mu \mathrm{A}$ for $5 \mathrm{~V} \mathrm{~s}^{-1}$.
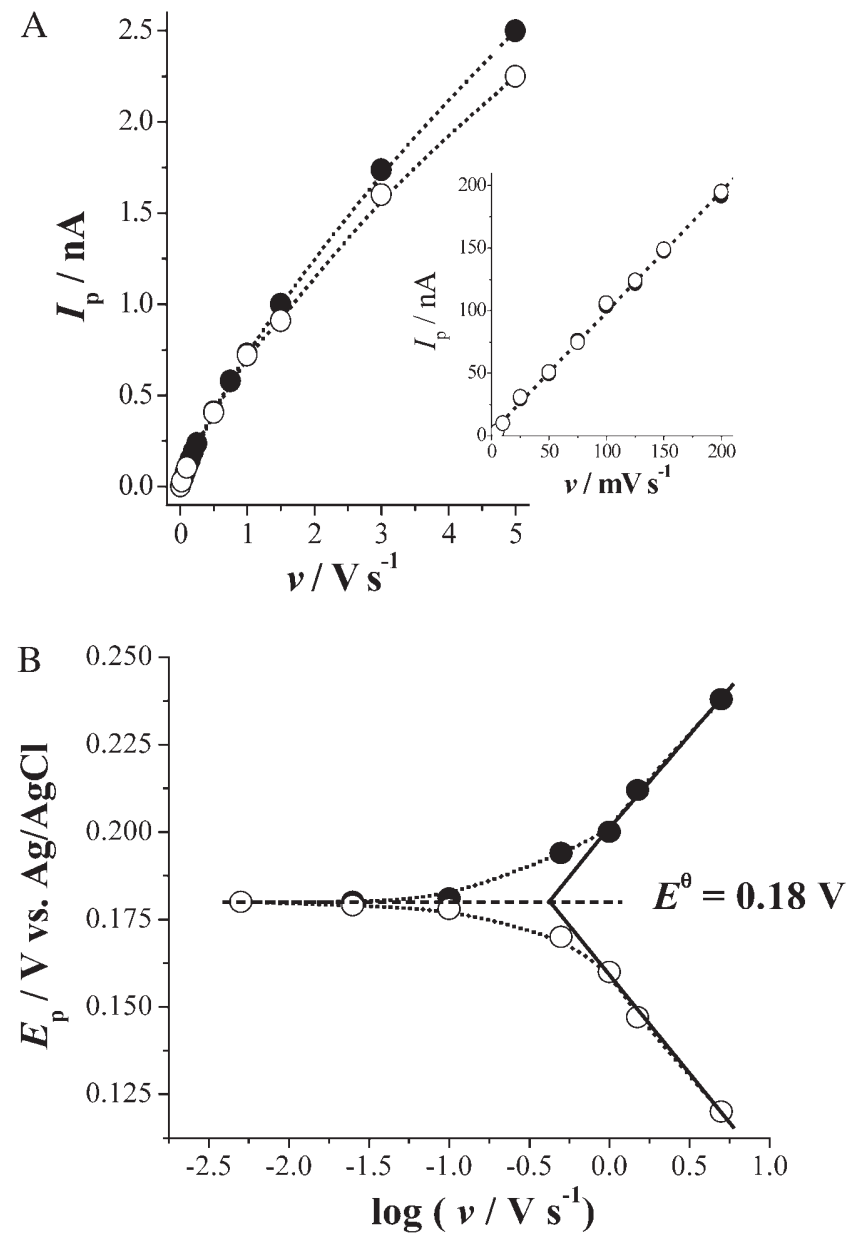

Fig. 6. A) Plot of (๑) $I_{\mathrm{pa}}$ and of $(\bigcirc) I_{\mathrm{pc}}$ of adsorbed $\mathrm{P}_{\text {glivec }}$ function of $v$. B) Plot of $(\bullet) E_{\mathrm{pa}}$ and $(\circ) E_{\mathrm{pc}}$ of adsorbed $\mathrm{P}_{\text {glivec }}$ function of $\log v$. scan rates on the peak current (ohmic drop) due to uncompensated resistance of the solution between working and reference electrode [18].

The influence of the scan rate on the anodic and cathodic peak potentials of adsorbed $\mathrm{P}_{\text {glivec }}$ was also investigated for $5 \leq v \leq 5000 \mathrm{mV} \mathrm{s}^{-1}$, Figure $6 \mathrm{~A}$. For $5 \leq v \leq 30 \mathrm{mV} \mathrm{s}^{-1}$ the peak potentials are not influenced by increasing scan rate.

For higher scan rates, $v \geq 300 \mathrm{mV} \mathrm{s}^{-1}$, the anodic and the cathodic peak potentials are displaced to more positive and to more negative values, respectively, following a linear relationship with $\log (v)$, Figure $6 \mathrm{~B}$. The slopes of these lines were calculated to be $59 \mathrm{mV} /$ decade. The two oblique asymptotes corresponding to the variation of peak potentials with $\log (v)$ for high scan rate intersect at the same point, the horizontal asymptote corresponding to the variation of the peak potentials with $\log (v)$ for low scan rates.

According to theoretical predictions [22], the slope of the variation of peak potential with $\log (v)$ for scan rates, when the system is not reversible, is given by $-2.3 R T\left(\alpha_{\mathrm{c}} n F\right)^{-1}$ for the cathodic peak and by $-2.3 R T\left[\left(1-\alpha_{\mathrm{c}}\right) n F\right]^{-1}$ for the anodic peak where $F$ is the Faraday constant, $R$ the ideal gas constant, $T$ the absolute temperature, $\alpha_{\mathrm{c}}$ the cathodic transfer coefficient and $n$ the number of electrons. In this particular case the sum of the anodic and cathodic transfer coefficients in unity. This allows the calculation of $\alpha_{\mathrm{c}} n=1$.

Also, the horizontal asymptote enables the determination of the surface standard potential $E^{\theta^{\prime}}=+180 \mathrm{mV}$ which, in the case of a reversible reaction when $v \rightarrow 0$, is equal to $E_{\mathrm{pa}}$ and $E_{\mathrm{pc}}$.

The intersection between the two linearly extrapolated lines occurs at $\log v=-0.40$. This value corresponds to a scan rate of $0.40 \mathrm{~V} \mathrm{~s}^{-1}$. Using the equation

$k_{0}=\alpha_{\mathrm{c}} n F v_{\mathrm{c}}(R T)^{-1}=\alpha_{\mathrm{a}} n F v_{\mathrm{a}}(R T)^{-1}$

the standard rate constant of the electrochemical reaction, $k_{0}$ was calculated to be $15.5 \mathrm{~s}^{-1}$.

\subsection{Square-Wave Voltammetry}

The advantage of using pulse voltammetric techniques for analytical and mechanistic studies is their ability to decouple the faradaic current from the capacitive current, especially in systems that involve adsorption of the reactants at the electrode surface [23, 24].

Another greater advantage of square-wave methods is the possibility to see during only one scan if the electrontransfer reaction is reversible or not. Since the current is sampled in both positive- and negative-going pulses, peaks corresponding to the oxidation and reduction of the electroactive species at the electrode surface can be obtained in the same experiment.

Square-wave voltammograms of adsorbed $\mathrm{P}_{\text {glivec }}$ were recorded in $\mathrm{pH} 4.70 .1 \mathrm{M}$ acetate buffer. For frequencies lower or equal to $50 \mathrm{~Hz}$, one main oxidation peak was observed at $E_{\mathrm{pa}}=+0.35 \mathrm{~V}$, and its current increased with 
increasing frequency, Figure 7A. The identical value of the potential of the $\mathrm{P}_{\text {glivec }}$ peak on the forward and backward current components (not shown) is an indication that the process occurs only on the GCE surface.

Increasing the frequency, and holding the step potential and pulse amplitude constant, led to splitting of the total current showing the transformation of the system into an irreversible one by increasing the scan rate, Figure 7A. This behavior is reflected in the total current due to the progressive displacement of the peak potentials obtained on the forward and on the backward currents, Figure 7B, and is characteristic of reversible electrode processes when the electrochemical species is adsorbed at the electrode surface $[23,24]$.

\subsection{Analytical Determination of Adsorbed Glivec}

Graphical integration of the anodic current - potential curve obtained at $v=5 \mathrm{mV} \mathrm{s}^{-1}$ gives the total charge $Q=3.5 \times$ $10^{-8} \mathrm{C}$ transferred during $\mathrm{P}_{\text {glivec }}$ oxidation. Supposing that, during one scan, all the adsorbed molecules are oxidized, the surface concentration of adsorbed $\mathrm{P}_{\text {glivec }}$ can be calculated as $\Gamma_{\text {Pglivec }}=Q(n F A)^{-1}=2.5 \times 10^{-12} \mathrm{~mol} \mathrm{~cm}^{-2}$, where $A$ is the geometrical electrode area in $\mathrm{cm}^{2}$. The symmetry of the wave shape allows the calculation of the surface concentration using $I_{\mathrm{pa}}=(4 R T)^{-1} F^{2} n^{2} v A \Gamma_{\text {Pglivec }}$, if a Langmuir isotherm behavior is obeyed [18]. For $v=5 \mathrm{mV} \mathrm{s}^{-1}$ the peak current $I_{\mathrm{pa}}=3.3 \mathrm{nA}$ and therefore $\Gamma_{\text {Pglivec }}=2.5 \times 10^{-12} \mathrm{~mol}$ $\mathrm{cm}^{-2}$.

Quantitation of glivec in solution has been carried out using two different procedures. The first followed glivec oxidation peak in solutions with different glivec concentrations in $\mathrm{pH} 4.50 .1 \mathrm{M}$ acetate buffer. During this procedure $\mathrm{pH} 4.5$ was used since previous results have shown that in this electrolyte higher glivec peaks can be obtained. The second procedure followed the oxidation peak of adsorbed $\mathrm{P}_{\text {glivec }}$ in $\mathrm{pH}$ 7.2 0.1 $\mathrm{M}$ phosphate buffer since it was shown in
Section 3.2 that in this electrolyte higher $\mathrm{P}_{\text {glivec }}$ oxidation peaks were obtained. Adsorption of $\mathrm{P}_{\text {glivec }}$ at the GCE surface was carried out from the glivec solution as described in Section 2.4, Procedure 3.

A linear dependence, Figure 8, of glivec oxidation peak current with concentration was obtained between $0.04 \mu \mathrm{M}$ up to $1 \mu \mathrm{M}$, given by the equation $I_{\mathrm{pa}}(\mathrm{nA})=0.94+29.6$ $C_{\text {Glivec }}(R=0.9998, N=9, S . D .=0.33)$. For the $\mathrm{P}_{\text {glivec }}$ peak, the concentration range of current linearity was $0.005 \mu \mathrm{M} \leq$ $C_{\text {Glivec }} \leq 0.100 \mu \mathrm{M}$ and the equation was: $I_{\mathrm{pa}}(\mathrm{nA})=2.61+$ $205 C_{\text {Glivec }}(R=0.9999, N=7$, S.D. $=0.02)$.

The sensitivity for the detection of glivec using the described method can be demonstrated by determining the limit of detection ( $L O D)$. The $L O D$ was determined as the drug concentration that caused a peak with a height three times the baseline noise level. Using the line param-

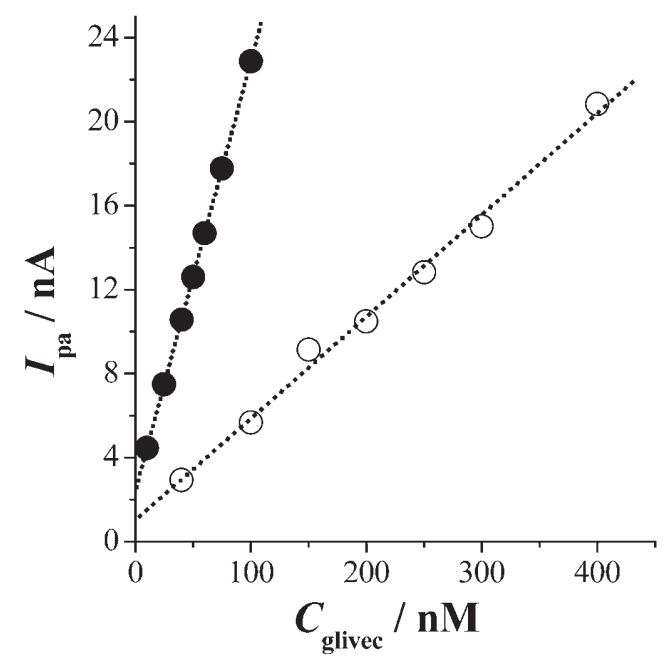

Fig. 8. Plot of $I_{\mathrm{pa}}$ of $(\mathrm{O})$ glivec oxidation peak in $\mathrm{pH} 4.50 .1 \mathrm{M}$ acetate buffer and of $(\bullet) \mathrm{P}_{\text {glivec }}$ oxidation peak in $\mathrm{pH} 7.20 .1 \mathrm{M}$ phosphate buffer. Adsorption of $P_{\text {glivec }}$ at the GCE surface was carried out as described in Procedure 3, Section 2.4.
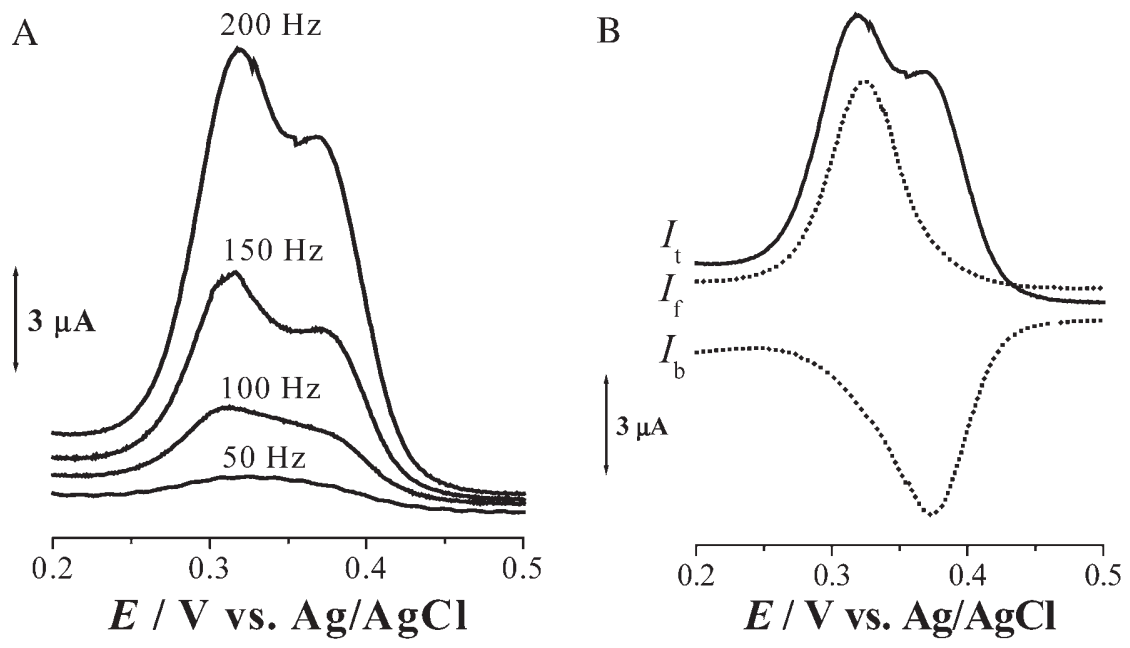

Fig. 7. SWV at A) increasing frequency and B) $v_{\text {effective }}=200 \mathrm{mV} \mathrm{s}^{-1}\left(f=200 \mathrm{~Hz}, \Delta E_{\mathrm{s}}=1 \mathrm{mV}\right)$ of adsorbed $\mathrm{P}_{\text {glivec }}$ in $\mathrm{pH} 4.30 .1 \mathrm{M}$ acetate buffer. 
eters of $I_{\mathrm{pa}}=I_{\mathrm{pa}}\left(C_{\mathrm{Glivec}}\right)$, the obtained $L O D$ following peak $1_{\mathrm{a}}$ was $L O D_{\text {glivec }}=3.3 \times 10^{-8} \mathrm{M}$, whereas following peak $3_{\mathrm{a}}$ the detection limit was $L O D_{\text {Pglivec }}=2.9 \times 10^{-10} \mathrm{M}$.

The quantitation limit $(L O Q)$ is the lowest concentration of a substance that can be quantitated with acceptable precision and accuracy. A typical signal/noise ratio of 10 is generally considered to be acceptable; therefore: $L O Q_{\text {glivec }}=1.1 \times 10^{-7} \mathrm{M}$ and for peak $3_{\mathrm{a}} L O Q_{\mathrm{Pglivec}}=$ $0.97 \times 10^{-9} \mathrm{M}$.

\section{Conclusions}

The antileukemia drug glivec undergoes oxidation at glassy carbon electrodes and involves the formation of an oxidation product, $\mathrm{P}_{\text {glivec }}$. The adsorption of $\mathrm{P}_{\text {glivec }}$ at the GCE surface yields a compact monolayer that inhibits further oxidation of glivec.

Due to the strong adsorption of $\mathrm{P}_{\text {glivec }}$ at the electrode surface, a detailed electrochemical study of this compound adsorbed at the GCE surface was carried out over a large $\mathrm{pH}$ range. The reversible redox reaction of the adsorbed $\mathrm{P}_{\text {glivec }}$ is $\mathrm{pH}$ dependent and occurs with the transfer of 2 electrons and 2 protons. Using cyclic voltammetry, the surface standard potential and the rate constant of the heterogeneous electrochemical reaction were calculated to be $E^{\circ \prime}=$ $+180 \mathrm{mV}$ and $k=15.5 \mathrm{~s}^{-1}$, respectively. The total surface concentration of adsorbed $\mathrm{P}_{\text {glivec }}$ was also calculated to be $2.5 \times 10^{-12} \mathrm{~mol} \mathrm{~cm}^{-2}$. The analytical determination of glivec was carried out by differential pulse voltammetry by measuring the anodic peak current corresponding to either the oxidation of glivec or the oxidation of $\mathrm{P}_{\text {glivec }}$ adsorbed on the GCE surface. The limits of detection of glivec and adsorbed $\mathrm{P}_{\text {glivec }}$ based on three times the noise level were $3.3 \times 10^{-8} \mathrm{M}$ and $2.9 \times 10^{-10} \mathrm{M}$, respectively.

\section{Acknowledgements}

Financial support from Fundação para a Ciência e Tecnologia (FCT), Post-Doctoral Grant SFRH/BPD/18824/2004 (V. C. Diculescu.), POCTI (cofinanced by the European Community Fund FEDER), and ICEMS (Research Unit 103).

\section{References}

[1] The Glivec International Site, http://www.glivec.com/about.

[2] D. Moffat, P. Davis, M. Hutchings, J. Davis, D. Berg, M. Batchelor, J. Johnson, J. O'Connell, R. Martin, T. Crabbe, J. Delgado, M. Perry, Bioorg. Med. Chem. Lett. 1999, 9, 3351.

[3] E. Buchdunger, A. Matter, B.J Druker, Biochim. Biophys. Acta. 2001, 1551, M11.

[4] D. L. Stirewalt, S. Meshinchi, J. P. Radich, Blood Rev. 2003, $17,15$.

[5] P. Zhang, W. Y. Gao, S. Turner, B. S. Ducatman, Mol. Cancer 2003, $2,1$.

[6] J. Li, J. Kleeff, J. Guo, L. Fischer, N. Giese, M. W. Büchler, H. Friess, Mol. Cancer, 2003, 2, 1.

[7] G. W. Krystal, Drug Resist. Updat. 2001, 4, 16.

[8] E. Weisenberg, J. D. Griffin, Drug Resist. Updat. 2001, 4, 22.

[9] G. Hoser, I. Majsterek, D. L. Romana, A. Slupianek, J. Blasiak, T. Skorski, Leukem. Res., 2003, 27, 267.

[10] R. Bakhtiar, J. Lohne, L. Ramos, L. Khemani, M. Hayes, F. Tse, J. Chromatogr. B. 2002, 768, 325.

[11] R. A. Parise, R. K. Ramanathan, M. J. Hayes, M. J. Egorin, J. Chromatogr. B. 2003, 791, 39.

[12] R. Bakhtiar, L. Khemani, M. Hayes, T. Bedman, F. Tse, J. Pharm. Biomed. Anal. 2002, 28, 1183.

[13] G. Guetens, G. De Boeck, M. Highley, H. Dumez, A. T. Van Oosterom, E. A. de Bruijn, J. Chromatogr. A. 2003, 1020, 27.

[14] D. Ivanovic, M. Medenica, B. Jancic, A. Malenovic, J. Chromatogr. B. 2004, 800, 253.

[15] J. R. Flores, J. J. Berzas, G. Castaneda, N. Rodriguez, J.Chromatogr. B. 2003, 794, 381.

[16] A. M. Oliveira Brett, J. A. P. Piedade, A. M. Chiorcea, J. Electroanal. Chem. 2002, 538-539, 267.

[17] J. Rodriguez, J. J. Berzas, G. Castaneda, N. Rodriguez, Talanta 2005, 66, 202.

[18] C. M. A. Brett, A. M. Oliveira Brett, Electrochemistry: Principles, Mmethods and Applications, Oxford Science University Publications, Oxford 1993.

[19] E. Laviron, J. Electroanal. Chem. 1974, 52, 355.

[20] A. T. Hubbard, F. C. Anson, in Electroanalytical Chemistry, Vol. 4 (Ed: A. J. Bard), Marcel Dekker, New York 1970, p. 129.

[21] A. P. Brown, F. C. Anson, Anal. Chem. 1977, 49, 1589.

[22] E. Laviron, J. Electroanal. Chem. 1979, 101, 19.

[23] J. J. O'Dea, J. Osteryoung, R. A. Osteryoung, Anal. Chem. 1981, 53, 695.

[24] J. Osteryoung, R. Osteryoung, Anal. Chem. 1985, 57, 101A. 